\title{
Heterotopic Pancreas Presenting as Gastric Polyp
}

\author{
Devinder P. Singh, Rohit Bansal* \\ Department of Surgery, Govt. Medical College and Rajindra Hospital, Patiala, India \\ Email: ${ }^{*}$ rohitbansal541@gmail.com
}

Received 2 February 2014; revised 1 March 2014; accepted 8 March 2014

Copyright @ 2014 by authors and Scientific Research Publishing Inc.

This work is licensed under the Creative Commons Attribution International License (CC BY). http://creativecommons.org/licenses/by/4.0/

\begin{abstract}
Heterotopic pancreas is defined as pancreatic tissue found outside the usual anatomical location of the pancreas. It is often an incidental finding and can be found at different sites in the gastrointestinal tract. It may become clinically evident when complicated by pathological changes such as inflammation, bleeding, obstruction, and malignant transformation. We report an unusual case of a 25-year-old male patient with pain epigastrium caused by a polyp at the body of stomach along greater curvature revealed at endoscopy. Endoscopic biopsy was s/o inflammatory pathology. Wide excision of polyp was done and a histological diagnosis of heterotopic pancreas was established. The difficulty of making an accurate preoperative diagnosis is highlighted.
\end{abstract}

\section{Keywords}

Heterotopic Pancreas, Gastric Polyp, Endoscopy, Surgery

\section{Introduction}

Heterotopic pancreas (HP), also known as ectopic, aberrant or accessory pancreas is defined as the presence of pancreatic tissue outside its normal location and without anatomic and vascular continuity with the main body of the pancreas [1]. Heterotopic pancreas is most commonly found in the stomach, duodenum and proximal jejunum, also it can occur anywhere in the gastrointestinal tract, pelvis, liver, biliary tract, spleen, omentum, mesentery, Meckel's diverticulum, and thorax. Heterotopic pancreas is usually found incidentally and is generally asymptomatic, but it may become symptomatic when complicated by inflammation, bleeding, obstruction or malignant transformation [2]. We report an unusual case of chronic epigastrium pain caused by Heterotopic pancreas in a young adult man.

\footnotetext{
${ }^{*}$ Corresponding author.
} 


\section{Case Report}

A 25-year-old man without any past medical history had developed epigastric pain, nausea over the last 10 - 12 weeks. Epigastric pain was refractory to treatment with proton pump inhibitors. He had never smoked, and drunk alcohol only occasionally. On examination, the patient was in good health, his abdomen was soft and nontender, with no palpable mass. He was afebrile, and his vital signs, respiratory and vascular systems were normal. Hematological examination and biochemical tests were within normal limits. Upper gastrointestinal endoscopy showed around-shaped, sessile polypoid submucosal lesion along the greater curvature of the gastric body, measuring $\sim 3 \mathrm{~cm}$ in diameter (Figure 1). Endoscopic biopsy was taken which was s/o inflammatory pathology. The patient opted for surgery because of his persistent symptoms (particularly pain). At surgery, a submucosal tumor $3.5 \times 3 \mathrm{~cm}$ located in body of stomach was found. The underlying mucosa was intact. Wide excision of polyp was carried out. Gross examination of the resected specimen showed that a well delimited mass with normal overlying mucosa located along the body of stomach. Microscopic examination of the lesion showed that pancreatic tissue with ducts, acini, and islets distributed from submucosa to serosa. The postoperative course was uneventful and the patient was discharged 4 days after surgery. He has remained free of symptoms follow-up at six months.

\section{Discussion}

The first case of Heterotopic Pancreas, developed in an ileal diverticulum, was reported by Jean Schultz in 1727, but the first histological confirmation was described by Klob in 1859 [3]. It is most commonly found in the stomach (25\% - 38\%), duodenum (17\% - 21\%), and proximal jejunum (15\% - 21\%), although it can occur anywhere in the gastrointestinal tract, pelvis, liver, biliary tract, spleen, omentum, mesentery, fallopian tube, Meckel's diverticulum, mediastinum, and lung. Heterotopic pancreas is usually asymptomatic and it is found during endoscopy, imaging or surgery, but it may become clinically evident depending on its size and the pathological changes (acute or chronic pancreatitis, cyst formation, malignant degeneration) [2]. The diagnosis of Heterotopic Pancreas is difficult as there are no specific diagnostic methods. Thus, in one series of 32 cases of symptomatic Heterotopic Pancreas, none of the patients was diagnosed preoperatively [4]. Imaging studies (EUS, $\mathrm{CT}$ ) are frequently used for the diagnosis of gastrointestinal submucosal tumor and can be helpful in the diagnosis of gastric Heterotopic Pancreas, but are not specific [5] [6]. Endoscopic biopsy performed by using standard biopsy forceps is most often unremarkable. The definitive diagnosis of HP is reached on the histopathological

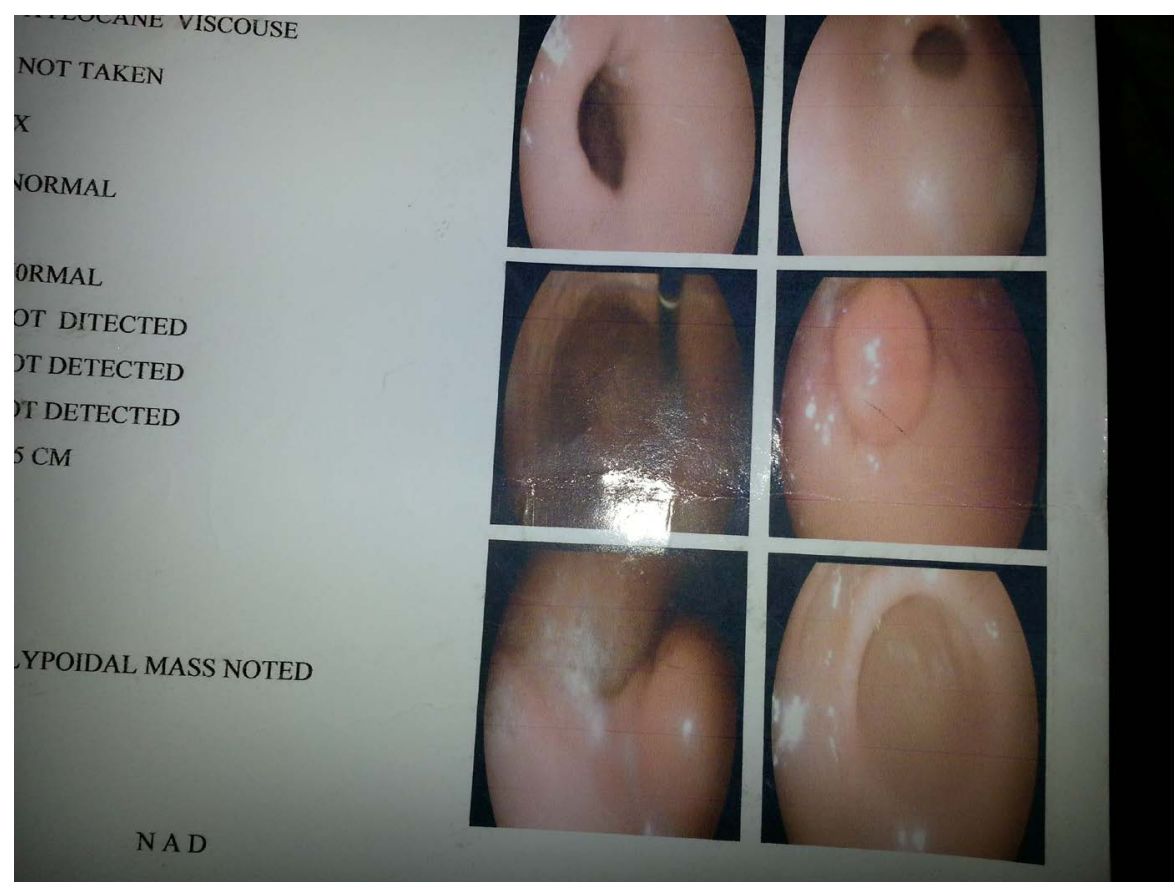

Figure 1. Endoscopy showing gastric polyp. 
examination of the tissue. Histologically, Heinrich in 1909 classified the HP into 3 types [7]: type 1, the most common, with all the components of the pancreas including acini, ducts and islets; type 2, with acini and ducts and no islets; type 3, with ducts alone. Our case belongs to type 1 . Later, the Heinrich classification was modified by Gaspar Fuentes, et al. [8] into 4 types: type 1, composed by acini, duct and islets similar to those seen in normal pancreas; type 2, composed of ducts only; type 3, consists of acini only (exocrine pancreas); type 4, composed of islets only (endocrine pancreas).

\section{Conclusion}

Cases of heterotopic pancreas are very rare and the preoperative diagnosis is difficult. However, heterotopic pancreas should be considered in the differential diagnosis of gastric tumor.

\section{References}

[1] Christodoulidis, G., Zacharoulis, D., Barbanis, S., Katsogridakis, E. and Hatzitheofilou, K. (2007) Heterotopic Pancreas in the Stomach: A Case Report and Literature Review. World Journal of Gastroenterology, 13, 6098-6100. http://dx.doi.org/10.3748/wjg.13.6098

[2] Monig, S., Selzner, M., Raab, M. and Eidt, S. (1996) Heterotopic Pancreas. Digestive Diseases and Sciences, 41, 1238-1240. http://dx.doi.org/10.1007/BF02088243

[3] Klob, L. (1859) Pancreas Accesorium. Zeitschrift der Kaiserl. Konigl. Gesellschaft der Aerzte zu Wien, 15, 732.

[4] Pang, L.C. (1988) Pancreatic Heterotopia: A Reappraisal and Clinicopathologic Analysis of 32 Cases. Southern Medical Journal, 81, 1264-1275. http://dx.doi.org/10.1097/00007611-198810000-00016

[5] Matsushita, M., Hajiro, K., Okazaki, K. and Takakuwa, H. (1999) Gastric Aberrant Pancreas: EUS Analysis in Comparison with the Histology. Gastrointestinal Endoscopy, 49, 493-497. http://dx.doi.org/10.1016/S0016-5107(99)70049-0

[6] Cho, S.J., Shin, K.S., Kwon, S.T., et al. (2000) Heterotopic Pancreas in the Stomach: CT Findings. Radiology, 217, 139-144. http://dx.doi.org/10.1148/radiology.217.1.r00oc09139

[7] Heinrich, H. (1909) Ein Beitrag zur Histologie des sogen. Akzessorischen Pankreas. Virchows Archiv für pathologische Anatomie und Physiologie und für klinische Medizin, 198, 392-401. http://dx.doi.org/10.1007/BF02085327

[8] Gaspar-Fuentes, A., Campos-Tarrech, J.M., Fernandez-Burgui, J.L., et al. (1973) Pancreatic Ectopias. Revista española de las enfermedades del aparato digestivo, 39, 255-268. 